\title{
THE IMPROVEMENT AND UTILIZATION OF TUSSOCK GRASSLANDS: A FARMER'S VIEWPOINT

\author{
I. H. WARDELL
} \\ Farmer, Lake Pukaki
}

The property to be discussed comprises 4,000 acres-2,000 acres of good and 2,000 acres of light, stony flat.

By 1956, the rabbit boards had the rabbit under control and stock numbers had risen from 240 ewes with a low lambing percentage, and clipping five bales of wool, to 600 ewes, 200 hoggets and a wool clip of 18 bales. Lambing percentage was 80.

By 1964 , ewe numbers had risen to 4,000 , lambing percentage was $83,80 \%$ of lambs were fattened, the clip was 120 bales, and gross income had multiplied 12 times. To support this carrying capacity were 1,000 acres of lucerne and 600 acres of oversown pasture; 12 miles of fence had been erected and fertilizer application had risen from nil to 60 tons annually.

Several factors influenced the start of development : the observation that a few pounds of lucerne seed thrown out on a very bare and exposed terrace grew extremely well; the valuable work on sulphur and molybdenum which was just beginning about 1957; the aeroplane which was making its presence felt as an agricultural implement; and the Australian Connor-Shea drill which made its appearance shortly afterwards.

In 1957, about 600 acres were sod-seeded with alsike and white clovers, with some cocksfoot, and sulphur. The re sults were spectacular, so much so that feed was out of all proportion to stock numbers-a common fault in development work.

With the means of growing abundant summer feed established, thought turned to lucerne for winter hay. An initial planting of 16 acres proved so successful that sowing was increased to 40 acres the following year, and subsequently to larger areas-300 acres in one year.

Just on 1,000 acres of lucerne was sown down straight out of tussock. It had 8 or 10 cuts with the chisel plough 
starting in late January. All but the final cultivation was completed before the winter freezeup. Sowing was done in the early spring. The normal sowing time in November was too late for a district with a drought period starting any time from late December. The discovery that dry heat will kill more young lucerne plants than intense cold was a major breakthrough. Good feed was available in January and February in the first year and enabled lambs to be sold fat. For those in debt an early return is vital.

Inoculation problems were very real until a farm advisory officer produced a successful inoculation seed by soaking seed, skim milk and water in a bath with the inoculant.

A first attempt to grow turnips for winter feed failed. A second attempt, in oversown clover country, produced good turnips in the old urine patches. Last year, they were tried again on land that had been five or six years in lucerne and topdressed every year. Yields were 47 tons per acre and 27 tons of swedes per acre. From now on, policy will be to build up fertility to grow turnips. Some cropping for winter feed, on land out of alsike and lucerne, has also been started. Oats have been up to ' 75 bushels and barley 50 bushels.

Thus, with large applications of sulphur superphosphate, it was possible to grow quantities of good feed, and, aided by the prevailing cheapness of merino sheep at Tekapo each March, stock numbers have risen rapidly. The figures for the years 1962-6 have been as follows: 1962, 2,500; $1963,2,800 ; 1964,4,000 ; 1965,4,000$ (dry year); 1966, 5,000 plus 300 cattle in summer.

In the future, a twelve-fold increase in present carrying capacity could be possible.

\section{Hindrances to the Future}

The utilization of feed has been, and still is a major problem. Instead of the present 28,000 bales of hay a year, 48,000 bales could be made. One can mob-stock with up to 12 ewes and their lambs per acre, fence and rotationally graze, but still the problem of effectively using all the feed is not overcome. This is one matter which farm advisors and scientists could take more seriously. Herbage production is increasing rapidly-but so is wastage. 
From the practical point of view, there is only one answer. Feed grown at considerable cost must be used effectively. The greater the cost the greater the need for efficiency. Until now, there had been only one way of doing this-to buy the poorest piece of country within a 20-mile radius to use as standing room. This insurance policy is like a dairyfarmer's run-off. It itself gets more fertile and productive and eventually provides a useful capital gain.

\section{Scientific Service}

Farmers in New Zealand are not being serviced properly. The Persians have 21 million sheep on dry hill country and have the plants to feed them, plus the grain. The West Australians have discovered and developed two new legumes in the last four years which alone will raise carrying capacity $3 / 4$ of a sheep per acre. The Australians also have a team of plant collectors in the Mediterranean who bring back many plants each year. In this country, effort in this sort of work is puny by comparison. There continues to exist the mistaken belief that ryegrass, white clover and Pinus radiata will do all that is necessary for New Zealand. Ariki ryegrass and Huia white clover are comparative failures. Another 30 million sheep could be added to the national stock tally-surely this prospect is worthy of more service than is available now. As a suggestion, more work could be done with alsike, prairie grass, tall fescue, phalaris, Yorkshire fog, tall oat grass, timothy, elymus, pampas grass, feed grain cereals, winter growing legumes and winter greenfeed.

What is required is first rate talent to study high country farming. There is not one scientist working on herbage utilization and animal production on a whole acre of tussock. It could fairly be questioned whether the scientist has actually increased carrying capacity of the tussock country by a quarter of a sheep per acre. Innovations have come from keen farmers with and without good extension assistance.

There have been recent impressive breakthroughs in agriculture in other countries. The Rockefeller program in the Philippines produced rice varieties with 26 times the increase in yield of previous varieties; that in Mexico increased the national wheat production yield by several 
times in a few years; the University of Washington produced a new wheat giving 21.9 bushels per acre on irrigated land.

In this country, the scientist has provided the tussock grassland farmer with only one tool-rhizobia-and he has not produced any new strains of that.

When 1 cwt of 1080 poison can produce more grass in tussock country then the output of a fertilizer works, probably $1 / 2$ ton of a new strain of rhizobia, which would help plants in the 3,000 to $4,000 \mathrm{ft}$ band, would be worth to New Zealand the value of a complete fertilizer works.

There may be a breakthrough coming in the tussock grasslands with high herbage production from high fertility and high stocking. But where are the winter feed tools to finish the job?

The New Zealand scientist is keenly measuring and systematizing the knowledge already available. This is good, but it is not enough. What is needed are more new tools, new techniques, new plants and new stock knowledge.

Tussock grasslands are areas where climate sets new limits and poses new problems. There must be scientists to work on these new problems.

\section{Fertilizer Price and Capital Cains}

If electricity is the spark of industry then superphosphate and its mixtures are the spark of agriculture. For electricity, it is considered necessary to charge practically the same price anywhere in New Zealand. Why, then, should superphosphate not be delivered to every farm airstrip at the same price? There should be no difference in delivery price to Auckland, Alexandra or Pukaki. There is the one disadvantage that such a scheme would, of course, increase the price of land slightly. But, in the main, capital gains are bought anyway, except for the occasional farmer who goes in to a district which is an agricultural vacuum, spends his money on development and then sells. This, in effect, is his patent which he sells. Usually capital gains are bought by reinvestment.

\section{Land Administration}

Would it not be in the country's interest to change the Land Act to something which will reward vigour, game- 
ness and contributors to the national cake? The Land Act is designed for the prosperity of the runholder who simply "holds". It should be redesigned for the reinvestors. Under present conditions, the Land Act is organized for income not growth.

There is something radically wrong when a good runholder says "we can only play at this farming". What can be done to alter the balance in favour of the developer? The following steps are suggested:

(1) Split leases-the right of progressive freehold on all land that will take and maintain a sward-then some money would be invested in the high country.

(2) Fertilizer free to the farm gate.

(3) Institute stock incentives instead of stock limitations.

(4) Direct available public money to those people who have the will to service farming.

As a further thought, one young vigorous re-investor is needed on the Tussock Grassland Institute because at present there appears to be no-one forcefully presenting the financial views of those farmers trying to spend more to produce more.

\section{Financial Conditions}

It is only right and logical that the State should find money for long-term development. Many farmers work for 5s. an hour or less and this is an asset the State can ill afford to lose. If it is to indulge in this form of discrimination, however, it must be prepared to give something in return-capital gains.

The Agricultural Production Council, after months of work, has created only one real benefit, the lending of money on a long-term basis for development by the State Advances Corporation.

The Council certainly tried many avenues and has possibly done much for some areas, but not one real disincentive appears to have been removed from tussock farming over the last three years, while the so-called incentives are fatuous.

There is a lot of truth in the remark: What is good for General Motors is good for America and what is good for 
farming is good for New Zealand. Stimulated exertions, crying opportunities, demand an expansive attitude from the governing body.

The object of modern farming is to produce as much real wealth as possible, and if this is to be done some risks are necessary. But under the present restrictive tax laws the incentive to take risks is lacking. Perhaps the reason that more figures on development work are not published is that far fewer farmers would undertake the work if such figures were freely available.

The farmer, from now on, must get his share of the national income. If, through increased production, New Zealand is to become more wealthy, it is oniy right that the farmer should have a reasonable share of the wealth.

Real development requires the active co-operation of the established farmer. But what benefit is there to him, if he wishes to keep a farm in the family? High tax ensures that for every extra effort expended, he receives less for what he produces-to the stage where he' reaches $6 \mathrm{~s}$. 8d. tax in the pound on his additional income.

Why should a man with a fencing strainer and a dog receive a similar income and more than the man using 100 tons of superphosphate, three men and three tractors? The country needs these peak actors and must be forced to give progressively greater reward for vigour. "Easy does it" is fine for the building sector, but not for the export sector. In expecting a more adequate return, the farmer is not asking for a privileged position in the community but only the right to produce and be fairly rewarded for it.

For two decades, the average farmer has been using the tools available to him and increasing his ewe numbers by 100 a year or more with little thought of capital increment. Once he increases his production by $100 \%$, the community has that increase for ever. But the farmer receives only $5 \%$ or $8 \%$.

Farming is free enterprise, but how can free enterprise work when a farmer cannot pay back what he borrows? The tax rate is iniquitous. The inflationary trend is probably only starting as far as costs are concerned, and farmers must ensure that they do not continue to be the chopping block. 
In his Presidential Address to this Association six years ago, the late Dr P. D. Sears calculated that "only about one-fifth of the $\mathrm{New}$ Zealand population is financially interested in agriculture and only little over half of these are directly sharing the risks and the profits of grassland farming". "People's interests", Dr Sears said, "lie where their money is. As long as urban industry is the only avenue for the ordinary investor, urban industry will loom largest in the people's minds. If the way were opened for more people to have a direct financial interest in $\mathrm{New}$ Zealand farming, there would be a much clearer appreciation of the proper role of farming as the natural basis of the whole national economy."

It could be that the continuing swing away from grassland farming as a basic activity might be reversed by getting joint stock enterprises into big areas of tussock. Larger company enterprises may not appeal to the small farmer on the plains but perhaps the tussock grasslands are made to order. There seems little point in expecting scientists, soil conservators, advisers and regulators, administrators and tax-gatherers to roll up their sleeves for grassland agriculture if the right to have a personal stake in the business is reserved to the private farmer.

There is little doubt that there are two words which will cover the farming scene. The first is knowledge and the second is vigour. Without more of the first and the right to use the second no progress whatsoever will be achieved.

Are there organizations which will accept the challenge to create a better social climate for farmers to grow and use more and better grass?

\section{DISCUSSION}

Would Mr Wardell give the stocking increases expected and the capital input required in the next five yews.

Sheep, 1,800; cattle, 1,500. -Input $£ 10,000$. 